\title{
COLLUM'S ANGLE AND CROWN ROOT ANGLE OF MAXILLARY INCISORS IN DIFFERENT MALOCCLUSIONS
}

\author{
Saadia Panezai, Nasrullah Mengal, Sadia Nisar Ahmed* \\ Sandeman Provincial Hospital Quetta Pakistan, *Bacha Khan Medical College Mardan Pakistan
}

\begin{abstract}
Objective: To determine Collum angle and crown to root angle of maxillary central incisor in different skeletal malocclusion.

Study Design: Comparative cross sectional study.

Place and Duration of Study: Orthondontics department, Bolan Medical College, Civil Sandman Hospital, Quetta, from Jun to Dec 2018.

Methodology: Data sample consisted of 140 lateral cephalograms. Sample consisted of 74 female cephalograms and 66 male cephalograms. The mean age of sampled subjects ranged between $21.62 \pm 5.96$ years. The Colum angle of the maxillary central incisors in each group was measured. SPSS version 21 was used to enter and process data. Comparison between Class II division 1 and division 2 collum angles was made by applying student t-test. Results: The average value for Collum angle in class II division 1 sample was $4.38 \pm 3.08$ with minimum being 0 and maximum 15 degree. The average values for Class II division 2 was $10.52 \pm 4.37$ with minimum 30 and a maximum 23 degree.

Conclusion: Maxillary central incisors in all malocclusions had significantly different mean Collum angles from zero. Paired sample t-test comparison showed that the Collum angle for maxillary central was much higher in Class II division 2.
\end{abstract}

Keywords: Collum angle, Class II division two, Maxillary central incisor.

This is an Open Access article distributed under the terms of the Creative Commons Attribution License (http://creativecommons.org/licenses/by/4.0), which permits unrestricted use, distribution, and reproduction in any medium, provided the original work is properly cited.

\section{INTRODUCTION}

Dissimilarity in morphological characteristics of maxillary central incisor can modify the therapy and retention phases of orthodontic treatment ${ }^{1}$. During Cephalometric tracing it is often observed that the long axis of root does not coincide with long axis of the crown. "The corresponding angle between these two longitudinal axes is defined as the crown to root angle. The Collum angle, therefore, is the supplementary angle of the crown to root angulation, used to correlate the angular difference between the two axes" 2 . According to Taylor ${ }^{3}$, crown root relationship has substantial diversity because they are disposed to disparity in curvature. This phenomenon is especially noticeable in individuals having Class II, division 2 malocclusions. In a research by Delivanis and Kuftinec ${ }^{4}$, it was established that in Class II division 2 patients, the inclinations of the

Correspondence: Dr Saadia Panezai, Senior Dental Surgeon, Sandeman Provincial Hospital, Quetta Pakistan

Received: 09 Sep 2020; revised received: 03 Oct 2020; accepted: 05 Oct 2020 maxillary central incisors have a greater propensity to be "bent" to the lingual more commonly compared to subject having other types of malocclusion. These abnormal findings have been propounded as possible etiological factor in the development of the deep bite observed in Class II, Division 2 patients. Furthermore, on this aspect of difference in morphological characteristics of central incisors involved in class II division 2 malocclusion a study observed that the shape characteristics of these teeth include axial bending and reduced labiopalatal thickness. A longer crown and a shorter root were also identified as prominent features of class II division 2 permanent maxillary central incisors ${ }^{5}$. Use of straight wire appliance on such teeth may result in root approximation to the lingual or palatal cortical plates. One of the important reasons for root resorption is application of inappropriate torque relative to the crown-root angulation, particularly in upper anterior teeth. If Collum's angle is ignored during treatment, this orthodontic maneuver 
will bring the root in close proximity to the cortical plate resulting in negative sequelae of root resorption ${ }^{6}$. Careful observation of Collum's angle will help achieve esthetic, functional and stable final treatment outcome ${ }^{3,7}$. Notwithstanding that computed tomography (CT) and conebeam CT (CBCT) endow three dimensional (3D) spatial and anatomical details, availing cephalometric radiographs imparts ample structural data regarding the central incisors. Moreover, conebeam CT and CT are not readily accessible as cephalometric radiographs in dental facilities, decreasing their applicability. Lateral cephalograms were used for this study for their easy access and affordability as patients coming to public hospitals belong to lower income strata. In this study determination of Collum angle was undertaken and variation between the class II division 1 and class II division 2 malocclusions were compared. The objective of this study was to find the comparison of Collum angle and crown to root angle of maxillary central incisor in different skeletal malocclusion.

\section{METHODOLOGY}

This was a comparative cross sectional study, undertaken at the department of orthodontics Bolan medical college, Civil Sandeman hospital, Quetta, from June to December 2018. A sample size of 140 was calculated using $95 \%$ confidence interval, $80 \%$ and taking magnitude of mean Collum angle i.e. $5.2 \pm 1.3$ o in class II division 2 and $0.1 \pm 0.7^{\circ}$ in class II division 1. Sampling technique employed was non probability, consecutive sampling. Lateral cephalograms of subjects having severe crowding in anterior region and mixed dentition were not included in the study. Additionally, for precise measurement of maxillary central incisor's collum angle on lateral cephalograms, subjects with prostheses (posts, dental implants, or fixed partial dentures) were not included as well. SPSS-21 was used to enter and analyzed the data. Quantitative data like Class I and II were presented as means and standard deviation. Student t-test was used to compare between Class II Div I and Div 2 Collum angle.

\section{Data Collection Procedure}

One hundred and forty patients presenting in the Department of Orthodontics, fulfilling the inclusion criteria were added in the study. Which comprised of 74 females and 66 males ranging in age from 9-40 years (mean age 21.62 \pm 5.96 years). Informed consent was obtained. Demographic details of patients (name, age) were obtained. The orthodontists divided patients into two groups depending on the malocclusion type utilizing Angle's classification of malocclusion as: Class-II division I, Class-II division 2 malocclusions. Outlines of the maxillary central incisor were drawn from lateral cephalograms. On the incisal edge, point superius was marked. The middle point of the cementoenamel junction was also marked. Both these points were joined to create the axis of the crown., and cementoenamel junction middle point was then joined with the root apex point to create the root's long axis. The Collum angle was then measured, as shown in figure.

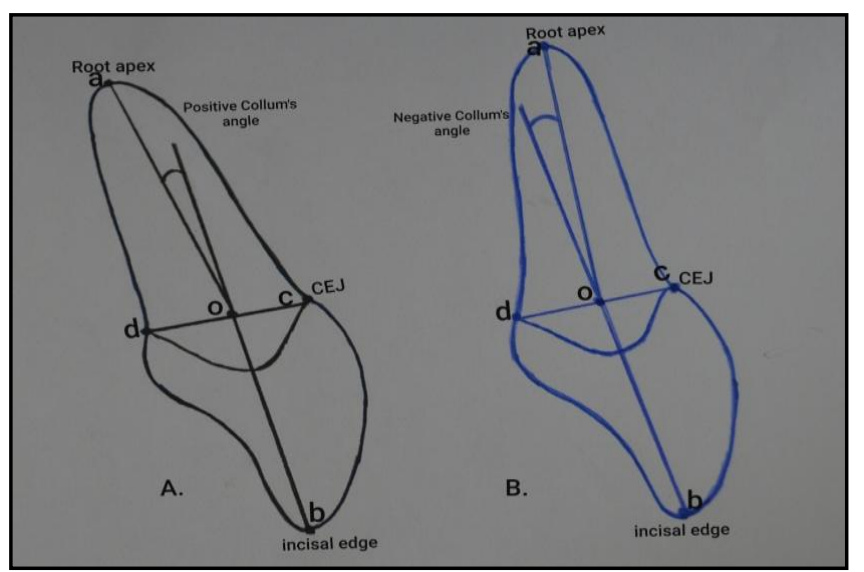

Figure: Measurement of Collum's angle (a). shows the positive Collum's angle, line ao is lingual to extension line. (b) shows a negative Collum's angle, line ao is labial to extension line.

\section{RESULTS}

Out of 140 patients, 77 (55\%) patients were in 12-20 years of age group, 39 (25.7\%) were between the age of $21-28$ years. Twenty four $(15.8 \%)$ were in 28-35 years of age. With 74 females $(52.85 \%)$, and $66(47.14 \%)$ male patients. Both class II division 1 and 2 groups had 70 sample size in each group. The average value for Collum 
angle in class II division 1 sample was 4.38 3.08 with minimum being 0 and maximum 15 degree. The average values for Class II division 2 was $10.52 \pm 4.37$ with minimum 30 and a maximum 23 degree (table-I). Paired sample t-test

Table-I: Descriptive statistics of Collum angle in different malocclusion types.

\begin{tabular}{l|l|l|l|l}
\hline $\begin{array}{l}\text { Malocclusion } \\
\text { type }\end{array}$ & (n) & $\begin{array}{c}\text { Mean } \\
\pm \text { SD }\end{array}$ & Minimum & Maximum \\
\hline Class II/2 & 70 & $\begin{array}{c}10.57 \\
\pm 4.37\end{array}$ & 3 degrees & 23 degrees \\
\hline Class II/1 & 70 & $\begin{array}{c}4.38 \pm \\
3.08\end{array}$ & 0 degrees & 15 degrees
\end{tabular}

comparison depicted that the Collum angle for maxillary central incisor for subjects with class II division 2 malocculusion was notably higher than class II division 1, (table-II).
Collum angle can be used as a supplementary angle to comprehensively study the crown to root angulation. Previous studies ${ }^{13-16}$. Established that significantly large Collum angles were found in individuals having class II division two or class III incisor relationships. The results of this study also show identical outcomes, it was carried out to evaluate the maxillary central incisor Collum's angle in a sample of Pakistani patients with different skeletal malocclusions using cephalometric radiographs. Mean Collum angles were of $10.57 \pm 4.37$ in Class II division 2 group, and $4.38 \pm 3.08$ in Class II Division 1 group. Studies undertaken in other centers in Pakistan showed similar patterns for Class II division 2 incisors, Zahra et al15, (mean Collum angle in class II division 2 was 15. 02 degrees) Israr et al16,

Table-II: Comparison of Collum angle between Class II division 2 \& 1 .

\begin{tabular}{l|c|c|c|c}
\hline \multirow{2}{*}{$\begin{array}{l}\text { Comparison of C1 II } \\
\text { div 2 Vs C1 II div 1 }\end{array}$} & $\begin{array}{c}\text { Mean } \\
\text { Difference }\end{array}$ & $\begin{array}{c}\text { Standard } \\
\text { Deviation }\end{array}$ & $p$-value & $\begin{array}{c}\text { 95\% Confidence Interval of } \\
\text { Difference }\end{array}$ \\
\cline { 2 - 5 } & 6.38 & 1.6 & $<0.001^{*}$ & $\begin{array}{c}\text { Lower Upper } \\
4.128 .31\end{array}$ \\
\hline
\end{tabular}

${ }^{*}$ Mean value significant at the 0.05 level.

\section{DISCUSSION}

During development, tooth morphology is subject to numerous environmental and genetic agents. Tooth crown mineralize physiologically before the tooth $\operatorname{root}^{9}$. In class II division 2 malocclusions, increased lip pressure and forces from perioral muscles and mastication process disturbs the eruptive path by torquing the crown lingually, which leaves the remaining of the root mineralization process to take place throughout the length of original path outlined by neurovascular triad of the tooth ${ }^{10}$. The dental characteristics include retroclined central incisors, often accompanied by proclined lateral incisors ${ }^{11}$. According to Backlund ${ }^{12}$, the large interincisal angle makes a gliding contact which builds insufficient axial stress on the teeth, which permits the teeth to reach beyond normal range of vertical overlap. The eruption will continue up to the level when pressure from growth is equalized by axial chewing forces or forces applied by soft tissues. (mean Collum angle in class II division 2 was $10.03 \pm 4.37$ degrees). In a study by Delivanis and Kuftinex ${ }^{4}$, fifty-three class II division II patients and fifty-three control patients, comprising of classifications other than Class II division two, were observed. Mean Collum angle for class II division two patients was $6.14 \pm 5.14$ degrees, compared to the control value of $1.52 \pm 4.36 \mathrm{deg}$ rees. However, this study lacked a normal Class I control group and this was the limitation of this study. Williamson and Woodhouse7, in their study inferred similar results of significant Collum angle in Class II division 2 compared to other malocclusions. Shen et al found comparable results in their study but with larger collum angles (5.3 \pm 4.2 degrees for Class II division 1 and $10.6 \pm$ 4.4 for class II division 2) they attributed this to different hereditary genes between western and oriental races. Also citing, that more protrusion in both jaws during bone development and greater axial tooth bending compensated for that bony protrusion, as the probable reasons for the diff- 
erence. Goma et al17, compared Collum's angle related to different vertical malocclusions. They found that the maxillary central incisor collum angle was highly significant, in horizontal grower than in vertical grower with a mean difference being $5.7^{\circ} \pm 1^{\circ}$. This supplements the finding that majority of class II div 2 individuals have lower mandibular plane angles and deep bites. Wang et al18, excluded samples of class II division 2 incisors because of proven Collum angle values. Cone beam computed tomography method was used for assessment of Collum angle. They compared the crown-root morphology of central incisors in different skeletal malocclusions and found that, Class II $\left(5.18 \pm 4.97^{\circ}\right)$ samples had significantly greater Collum angle compared with Class I $\left(-1.02 \pm 6.30^{\circ}\right)$ and Class III $\left(0.43 \pm 5.44^{\circ}\right)$ in maxillary, and in mandibular, the Class III (5.59 \pm $5.64^{\circ}$ ) samples presented significantly greater Collum angle compared with Class I $\left(0.40 \pm 5.80^{\circ}\right)$ and Class II $\left(0.82 \pm 5.7^{\circ}\right)$. In another study ${ }^{19}$, Maxillary central incisor crown root relationships in class I normal occlusions and class III open and deep malocclusions was done, and they concluded that in class III deep bite cases Collum angle and labial crown root angles had statistically higher values than patients with normal class I and class III open bite malocclusions. Srinivasan ${ }^{20}$, emphasized the etiological contribution of lower lip position to collum angle, it was concluded that a definite association is suggested between collum angle and location of lower lip line. As the lower lip line level extended to incisal one third to middle one third, collum angle was positive and increased. On the other hand, with lip line level at cervical third, collum angle decreased and was negative.

Despite several innovations since straight wire appliance discovery in 1972, its use is still very popular amongst orthodontists. Andrew's straight wire appliance was designed to avoid the difficult and time consuming task of wire bending. He built first, second and third order bends within the bracket. However, these bracket prescriptions may have integrated the erroneous premise in their design that crown root angles are zero degrees for all teeth. Due to an extensive variation in tooth morphology, bracket positioning errors, and different bracket prescriptions, torque expression is greatly influenced ${ }^{21}$. Collum angle is an essential factor that controls the root apex position during orthodontic therapy. One of the detrimental factors for the causation of external apical root resorption could be the iatrogenic proximity of cortical plate with the roots of anterior teeth, and this was thought to be significant in relation to the degree of root resorption $^{22}$. In addition, large collum angles means more deflected crown root angles, such anatomic features can hinder intrusive and extrusive tooth movements ${ }^{23}$. This also limits the amount of torque that can be applied without damaging the root or cortical plate ${ }^{24}$.

Research studies point out to the fact that the maxillary incisors in Class II division 2 cases are different and this difference should be considered carefully before undertaking orthodontic treatment ${ }^{25}$. It is recommended to closely evaluate the position of the central incisor roots and the anatomic structure of the surrounding bone in Class II, Division 2 patients ${ }^{17}$. Heravi ${ }^{6}$ concluded that when force is applied, maxillary central incisor retraction in class II, division 2 patient, the resulting force may be 1.18 times heavier than in class I subjects. Genetics and high position of lower lip line are possible etiology factors for the development of this malocclusion. Collum angle affects the root position in orthodontic treatment. Due to improper torque, roots can move into cortical bone resulting in resorption. Moreover, efficiency of incisor intrusive and extrusive mechanism can be slowed or impeded.

\section{CONCLUSION}

There is great variation in incisor morphology amongst different malocclusions. In this study, Collum's angle was found to be significantly greater in class II division 2 malocclusion cases. With large deviations, custom made brackets, indirect bonding systems, wire bending during orthodontic treatment should be considered. 


\section{CONFLICT OF INTEREST}

This study has no conflict of interest to be declared by any authors.

\section{REFERENCES}

1. Bryant R, Sadowsky P, Dent M, Hazelrig J. Variability in three morphologic features of the permanent maxillary central incisor. Am J Orthod 1984; 86(1): 25-32.

2. Ma ESW. Differential CBCT analysis of Collum angles in maxillary and mandibular anterior teeth in patients with different malocclusions, UNLV These, Dissertations, Professional Papers, and Capstones; 2016 Avalibal at [Internet] p.2880. https:// digitalscholarship.unlv.edu/cgi/viewcontent.cgi?article $=3883 \&$ context=thesesdissertations.

3. Taylor R. Variation in form of human teeth: II. An anthropologic and forensic study of maxillary canines. J Dental Res 1969; 48(2): 173-82.

4. Delivanis HP, Kuftinec MM. Variation in morphology of the maxillary central incisors found in Class II, division 2 malocclusions. Am J Orthod 1980; 78(4): 438-43.

5. McIntyre GT, Millett DT. Crown-root shape of the permanent maxillary central incisor. The Angle Orthodontist 2003; 73(6): 710-15.

6. Heravi F, Salari S, Tanbakuchi B, Loh S, Amiri M. Effects of crown-root angle on stress distribution in the maxillary central incisors' PDL during application of intrusive and retraction for-ces: a three-dimensional finite element analysis. Progress Orthodontics 2013; 14(1): 26-30.

7. Williams A, Woodhouse C. The crown to root angle of maxillary central incisors in different incisal classes. British journal of orthodontics 1983; 10(3): 159-61.

8. Shen YW, Hsu JT, Wang YH, Huang HL, Fuh LJ. The Collum angle of the maxillary central incisors in patients with different types of malocclusion. J Dental Scie 2012; 7(1): 72-76.

9. Li J, Parada C, Chai Y. Cellular and molecular mechanisms of tooth root development. Development 2017; 144(1): 374-84.

10. Harris EF, Hassankiadeh S, Harris JT. Maxillary incisor crownroot relationships in different angle malocclusions. Am J Orthod Dentofacial Orthop 1993; 103(1): 48-53.

11. McIntyre GT, Millett DT. Crown-root shape of the permanent maxillary central incisor. Angle Orthodontist 2003; 73(6): 710-15.

12. Backlund E. Tooth form and overbite. Trans Eur Orthod Soc 1960; 36(1): 97-03.

13. Feres MFN, Rozolen BS, Alhadlaq A, Alkhadra TA, El-Bialy T. Comparative tomographic study of the maxillary central incisor collum angle between Class I, Class II, division 1 and 2 patients. J Orthodontic Sci 2018; 7(1): 6-9.

14. Shailaja A, Gowda C, Gowda S. The collum angle of Maxillary Central Incisors in different skeletal malocclusions-A Cephaometric study. Int J Applied Dental Sci 2016; 2(03): 33-36.

15. Khalid Z, Iqbal K, Khalid S, Riaz A, Jan A. Comparison of Collum Angle of Maxillary Central Incisors in Different Incisor Relationships. J Coll Physicians Surg Pak 2020; 30(05): 471-75.

16. Israr J, Bhutta N, Chata MR. Comparison of Collum Angle of Maxillary Central Incisors in Class II div1 \& 2 Malocclusions. Pakistan Oral Dental J 2016; 36(1): 91-94.

17. Gomaa N, Elmarhoumy S, Fakhry N. Maxillary Central Incisors' collum angle in different skeletal vertical malocclusions-A Cephaometric study. Egyptian Dental J 2015; 65(1): 1-7.

18. Wang XM, Ma LZ, Wang J, Xue H. The crown-root morphology of central incisors in different skeletal malocclusions assessed with cone-beam computed tomography. Prog Orthod 2019; 20(1): 20-30.

19. Fuller Jessica Kay. Maxillary central incisor crown-root relationships in class I normal occlusions and class III open and deep malocclusions. MS (Master of Science) thesis, University of Iowa, 2015. https:// doi.org/10.17077/etd.3m3hm2ph

20. Srinivasan B, Kailasam V, Chitharanjan A, Ramalingam A. Relationship between crown-root angulation (collum angle) of maxillary central incisors in Class II, division 2 malocclusion and lower lip line. Orthodontics (Chic.) 2013; 14(1): e66-e74.

21. Papageorgiou SN, Sifakakis I, Keilig L, Patcas R, Affolter S, Eliades $\mathrm{T}$, et al. Torque differences according to tooth morphology and bracket placement: a finite element study. Eur J Orthod 2017; 39(4): 411-18.

22. Horiuchi A, Hotokezaka H, Kobayashi K. Correlation between cortical plate proximity and apical root resorption. Am J Orthod Dentofacial Orthop 1998; 114(3): 311-18.

23. Pai SS, Panda S, Pai V, Anandu M, Vishwanath E, Suhas AS Effects of labial and lingual retraction and intrusion force on maxillary central incisor with varying collum angles: A threedimensional finite elemental analysis. J Ind Orthod Soc 2017; 51(1): 28-37.

24. Knosel M, Jung K, Attin T, Engelke W, Kubein-Meesenburg D, Gripp-Rudolph L, et al. On the interaction between incisor crown-root morphology and third order angulation. Angle Orthod 2009; 79(3): 454-61.

25. Kong WD, Ke JY, Hu XQ, Zhang W, Li SS, Feng Y. Applications of cone-beam computed tomography to assess the effects of labial crown morphologies and collum angles on torque for maxillary anterior teeth. Am J Orthodontics Dentofacial Orthopedics 2016; 150(5): 789-95. 